\title{
PRELIMINARY DISCUSSION OF THE CORRELATION BETWEEN ILLITERACY AND MORTALITY IN AMERICAN CITIES.*
}

\author{
BY RAYMOND PEARL AND MORRILL L. ILSLEY.
}

(Received for publication, May 22, 1922.)

\section{INTRODUCTION.}

In a recent review of the vital statisties of this country Pearl (1921) was impressed by the thought that one of the greatest difficulties with which the health officer has to contend, in his efforts to ameliorate the conditions which make for morbidity and mortality, must surely be the ignorance of great masses of the population with which he has to deal. So much of effective publie health work goes back, upon final analysis, to a basis of personal hygiene, that the dense ignorance and, what is worse, sheer stupidity of a not negligible fraction of our population must be a limiting factor. No attempt, however, so far as we are aware, has ever been made to evaluate statistically this relation. It has seemed desirable to undertake, in a preliminary way, the examination of certain data bearing upon the matter.

The attempt to measure intelligence precisely is a rather new departure in psychology, and none of the results of such endeavors may as yet be safely transferred from the special classes upon which they have been made to the general population. We are lacking, perhaps fortunately, any preeise general statistics as to the average intelligence (or stupidity), or the cistribution of grades of intelligence, in the population as a whole. The nearest approach to such data is found in the statisties of illiteracy.

This approach is obviously not close. An illiterate person may be, and not seldom is, naturally rather above the average in intelligence. Conversely, many literate persons are very feeble intellectually. But, with all due regard to these trite facts, it remains undeniable that, in a broad statistical sense, the illiteracy percentage of a community is a rough index of the extent to which that commu-

* Papers from the Department of Biometry and Vital Statistics, School of Hygiene and Public Health, Johns Hopkins University. No. 62. 
nity, as a group or population, falls short in its average equipment for meeting the battle of existence. In the complex and highly integrated social organization of present-day man in urban population aggregates, ability to read and write is a major asset in maintaining that general awareness of one's surroundings which is so vital an element in the struggle for existence. Those persons who lack this ability are unquestionably, on the average, of a rather low grade of general intelligence, even though there may be occasional brilliant exceptions. Furthermore it cannot be denied that the illiterate person is ignorant, as compared with the literate, on the average.

There are available, in the reports of the Census Bureau, data as to the number of illiterates and their proportion to the total population in all significant demographic units. Recognizing fully that percentage of illiteracy is not a precise index of the average ignorance of a population, we have nevertheless thought it worth while to examine the correlation of this variable with mortality.

The following general data on illiteraey in the United States, as revealed in the 1910 and earlier census counts, are of interest for purposes of orientation. (Cf. Talbot, W., 1916.) Roughly, five and a half million people in this country were illiterate in 1910. Of these, over a million conld speak no English. The census divided the illiterates into four classes: native white $(1,534,272)$, foreign born $(1,650,361)$, negro $(2,227,731)$, others $(103,859)$. The negro illiterates decreased from $3,150,000$ in 1880 to $2,227,731$ in 1910 , native born white illiterates decreased from 2,255,460 to $1,534,272$, and after 1890 there was a decrease of illiteracy among native born of native parents from $1,890,723$ to $1,378,884$ in 1910 , while among native born of foreign or mixed parentage the change was from 174,280 to 155,388 .

The number of illiterates steadily increased (up to 1910 at least) in Massachusetts, Rhode Island, Connecticut, New York, New Jersey, Pennsylvania, Illinois, North Dakota, Nebraska, Montana, Wyoming, Colorado, New Mexico, Arizona, Utah, Nevada, Washington, California. The greatest increase was in the New England and Middle Atlantie States, there having been an increase of approximately 140 per cent. in twenty years in these states, while on the other hand there was a decrease of thirty per cent. in the same period in the South Atlantic States.

The percentage of illiteracy in the United States was lowered 
TABLE I.

Percentage of uliterchy among native whites, the foreign born, and negroes at certain periods. Census data.

\begin{tabular}{|c|c|c|c|c|}
\hline Class. & 1880. & 1890. & 1900. & 1910. \\
\hline \multicolumn{5}{|l|}{ Native white } \\
\hline Per cent. of total population.......... & 73.5 & 73.0 & 74.5 & 74.4 \\
\hline Per cent. of illiteracy $\ldots \ldots \ldots \ldots \ldots$ & 9.4 & 6.2 & 4.6 & 3.0 \\
\hline \multicolumn{5}{|l|}{ Foreign born } \\
\hline Per cent. of total population. . . . . . . . & 13.1 & 14.5 & 13.4 & 14.5 \\
\hline Per cent. of illiteracy $\ldots \ldots \ldots \ldots$ & 12.0 & 13.5 & 12.9 & 12.7 \\
\hline \multicolumn{5}{|l|}{ Negroes } \\
\hline Per cent. of total population......... & 13.1 & 11.9 & 11.6 & 10.7 \\
\hline Per cent. of illiteracy,............. & 68.0 & 57.1 & 44.5 & 30.4 \\
\hline
\end{tabular}

during twenty years from 13.3 per cent. in 1890 to 10.7 in 1900 and 7.7 in 1910 ; but the number of foreign born illiterates increased 43 per cent. in the same pediod.

More than two thirds of all illiterates were in 1910 country dwellers $(3,748,031)$, of whom $1,342,372$ were native whites, 477,870 foreign born, 1,834,458 negroes. The illiterates in cities were divided thus: 191,900 native whites, $1,172,491$ foreign born, 393,273 negroes. Therefore the rural illiteracy problem lies with the negroes and native whites, and the urban with the foreign born. Foreign born illiterates are mainly in towns and cities of the New England States $(222,030)$, Middle Atlantic States $(582,756)$, East North Central States $(217,771)$; native white illiterates mainly in rural communities of the South Atlantic States $(400,507)$, East South

TABLE II.

Age distribution of aliterates in 1910.

\begin{tabular}{c|c|c|c|c}
\hline Age. & Number. & Per cent. & White (per cent.). & Negro (per cent.) \\
\hline $10-14 \ldots \ldots \ldots \ldots$ & 370,136 & 6.7 & 1.8 & 18.9 \\
$15-19 \ldots \ldots \ldots$ & 448,414 & 9.0 & 2.8 & 20.3 \\
$20-24 \ldots \ldots \ldots \ldots$ & 622,073 & 11.2 & 4.6 & 23.9 \\
$25-34 \ldots \ldots \ldots \ldots$ & $1,102,384$ & 19.9 & 5.2 & 24.4 \\
$35-44 \ldots \ldots \ldots \ldots$ & 940,510 & 17.0 & 5.4 & 27.7 \\
$45-54 \ldots \ldots \ldots \ldots$ & 829,153 & 15.0 & & \\
$55-64 \ldots \ldots \ldots$ & 607,754 & 11.0 & 6.7 & 52.7 \\
$65 \ldots \ldots \ldots \ldots$ & 573,799 & 10.4 & 9.4 & 74.5 \\
\hline
\end{tabular}


Central States $(362,178)$, West South Central States $(217,719)$; and negroes, who are illiterate, mainly in rural communities of the South Atlantic States $(810,526)$, East South Central States (581,250), West South Central States $(411,370)$.

The age distribution of the illiterate population in 1910 was as shown in Table II.

Table III shows the distribution of illiteracy by states in 1910 .

TABLE III.

\begin{tabular}{|c|c|c|}
\hline Iowa $\ldots \ldots \ldots \ldots \ldots \ldots \ldots 1.7$ & New York ............ & 5.5 \\
\hline Nebraska . . . . . . . . 1.9 & New Jersey .......... & 5.6 \\
\hline Oregon $\ldots \ldots \ldots \ldots \ldots \ldots$ & Oklahoma $\ldots \ldots \ldots \ldots$ & E.6 \\
\hline Washington $\ldots \ldots \ldots \ldots 2.0$ & Pennsylvania .......... & 5.9 \\
\hline Idaho $\ldots \ldots \ldots \ldots \ldots \ldots, 2.2$ & Conneetieut $\ldots \ldots \ldots \ldots$. & 6.0 \\
\hline Kansas $\ldots \ldots \ldots \ldots \ldots \ldots 2.2$ & Nevada $\ldots . \ldots \ldots \ldots \ldots$ & 6.7 \\
\hline Utah $\ldots \ldots \ldots \ldots \ldots \ldots 2.5$ & Maryland . . . . . . . . & 7.2 \\
\hline South Dakota ......... 2.9 & Rhode Island . . . . . . . . & 7.7 \\
\hline Minnesota $\ldots \ldots \ldots \ldots \ldots, 3.0$ & Delaware $\ldots \ldots \ldots \ldots \ldots$ & 8.1 \\
\hline Indiana $\ldots \ldots \ldots \ldots \ldots \ldots .3 .1$ & West Virginia $\ldots \ldots \ldots \ldots$ & 8.3 \\
\hline North Dakota . . . . . . . 3.1 & Texas $\ldots \ldots \ldots \ldots \ldots$ & 9.9 \\
\hline Michigan $\ldots \ldots \ldots \ldots \ldots .3 .2$ & Kentucky $\ldots \ldots \ldots \ldots \ldots$ & 12.1 \\
\hline Ohio $\ldots \ldots \ldots \ldots \ldots \ldots .3 .2$ & Arkansas $\ldots \ldots \ldots \ldots \ldots$ & 12.6 \\
\hline Wiseonsin $\ldots \ldots \ldots \ldots \ldots 3.2$ & Tennessee $\ldots \ldots \ldots \ldots$ & 13.6 \\
\hline Wyoming $\ldots \ldots \ldots \ldots \ldots, 3.3$ & Florida $\ldots \ldots \ldots \ldots \ldots$ & 13.8 \\
\hline Galifornia $\ldots \ldots \ldots \ldots \ldots 3.7$ & Virginia ............. & 15.2 \\
\hline Colorado $\ldots \ldots \ldots \ldots \ldots 3.7$ & North Carolina ......... & 18.5 \\
\hline Illinois $\ldots \ldots \ldots \ldots \ldots \ldots .3 .7$ & New Mexico ........... & 20.2 \\
\hline Vermont $\ldots \ldots \ldots \ldots \ldots 3.7$ & Georgia $\ldots \ldots \ldots \ldots \ldots$ & 20.7 \\
\hline Maine $\ldots \ldots \ldots \ldots \ldots \ldots 4.1$ & A,rizona $\ldots \ldots \ldots \ldots \ldots$ & 20.9 \\
\hline Missouri $\ldots \ldots \ldots \ldots \ldots 4.3$ & Mississippi $\ldots \ldots \ldots$ & 22.4 \\
\hline New Hampshíre $\ldots \ldots \ldots, 4.6$ & Alabama $\ldots \ldots \ldots \ldots$ & 22,9 \\
\hline Montana $\ldots \ldots \ldots \ldots \ldots 4.8$ & South Carolina ......... & 25.7 \\
\hline Dist. of Columbia . . . . . 4.9 & Louisiana $\ldots \ldots \ldots \ldots$ & 29.0 \\
\hline
\end{tabular}

II. Data and Plan.

In this preliminary examination of the problem, undertaken to see whether a more detailed statistical analysis would be warranted, the following data were extracted on cards for 460 eities of a population of 10,000 or over in 1910, in the Registration Area for deaths. The figures were taken from the 1910 Census (Population) and Mortality Statistics for 1910. The "subscript numbers" are those which will be used in that position to designate the variables in the correlations. 


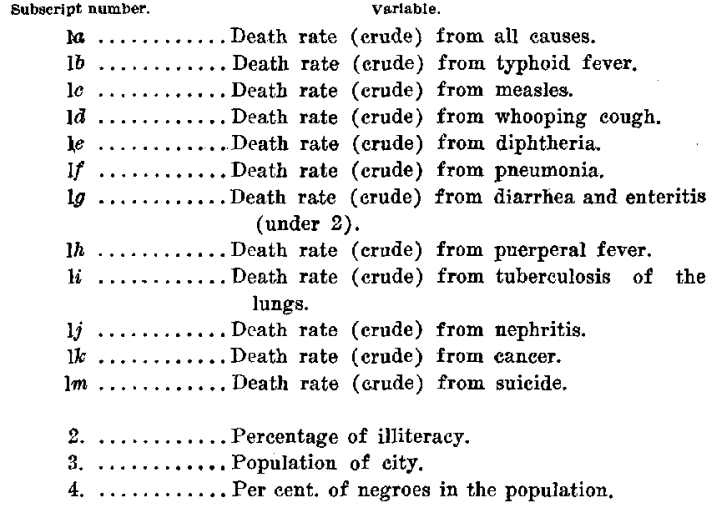

The cards were used to form correlation tables relating the several variables to each other, and from the zero order correlation coefficients computed from these tables, there were calculated partial correlation coefficients of the form $r_{12,34}$ by the usual methods ( $c f$. Yule, 1907). All basic zero-order tables gave linear regressions.

It will be seen from the above outline of procedure that the results of this first study can in no wise be regarded as final. They merely indicate the general trend of the situation, and must be refined in several directions before they can be accepted as definitive. In particular it will be necessary: $(a)$ to correct for differenees in the age distributions of the populations; $(b)$ to inelude data as to proportion of foreign born in each community; (c) to eliminate the element of spurious correlation (cf. Pearson, K., 1896, and Reed, L. J., 1921) which arises in the present study by virtue of the fact that in variables 1 and 2 the denominator of the rate fraction is identical, namely, the total population; and $(d)$ to correct for geographieal distribution of the cities included. We expect, in a much more detailed paper to follow the present one, to carry out all these refinements as well as certain others, but in the meantime it seems advisable, in view of the large amount of computing which must still be done before the final report can be finished, to put on record our preliminary rough findings. We feel confident from results already in hand that the picture presented in this paper will not be altered 
in the broad outline, by the more refined analysis, and at the same time we believe that the results are a distinct contribution to the general philosophy of public health administration in this country.

Regarding the official definition of illiteracy, the following may be quoted from the Census of 1910 (Vol. I, p. 1185):

The population schedule for the census of 1910 , like those for several previons censuses, contained two inquiries relating to illiteracy, namely, as to whether the person enumerated was able to read and as to whether he was able to write. Under the instructions to enumerators, ability to read or write in any languagenot necessarily English-called for an affirmative answer. Answers to these questions were required only for persons ten years of age and over.

For the present report, the Bureau of the Census has classified as illiterate all persons unable to write regardless of ability to read. A limited number of persons were reported as able to read though not able to write, but the statistics in regard to this class have not seemed of sufficient importance to call for a separate presentation. . . . In general, the "literate" population in this report should be understood as including all persons who have had even the slightest amount of schooling, while the illiterates represent persons who have had no schooling whatsoever.

\section{Results.}

\section{All causes.}

The pertinent net correlations are:

$$
\begin{aligned}
& r_{1^{a_{2} \cdot 84}}=+.333 \pm .028 \\
& r_{1^{a_{3.24}}}=+.016 \pm .031 \\
& r_{1^{a_{4} \cdot 23}}=+.359 \pm .027
\end{aligned}
$$

From these data it is seen that:

There is a moderately high, but entirely significant (coefficient $>10$ times its probable error) eorrelation between the death rate from all causes and percentage of illiteracy in these eities, when both absolute size of population and percentage of negroes in the population are held constant. In other words, just as we expected at the outstart, from a priori considerations, the degree of illiteracy of the population does appear to influence significantly its death-rate.

There is no significant correlation between the absolute size of a city and its death-rate, when the percentages of illiteracy and of negroes are held constant.

There is a significant positive correlation, as we should expect, between death-rate and percentage of negroes, when both illiteracy and absolute size of population are held constant. This is of the same order of magnitude as the net correlations between illiteracy 
and death-rate. It means that the negro is an important element in determining community death-rates, quite apart from his illiteracy.

\section{Typhoid fever.}

The coefficients are:

$$
\begin{aligned}
& r_{1 b_{2.34}}=-.046 \pm .031 \\
& r_{1 b_{3.24}}=-.085 \pm .031 \\
& r_{1 b_{4.23}}=+.180 \pm .030
\end{aligned}
$$

There is no significant net correlation between the death-rate from typhoid fever and either percentage of illiteracy or absolute size of population. This is precisely what would be expected, because of the nature of the disease, and particularly the methods of its control. In American cities at the present time it can possibly mean but little, if anything, to an individual's chances of contracting typhoid whether he is intelligent or stupid as an individual. The control of the chances of contracting typhoid is essentially a community matter and is handled as such.

There is a small, but statistically significant net correlation between the typhoid death-rate and the percentage of negroes. At its face value this would indicate a greater racial susceptibility to this disease in the negroes than in the whites. Until a more complete analysis of the statistieal data along the lines indicated above has been made, however, such a conelusion must be held in abeyance, as the existence of other factors not taken account of in the present study may bring about the result we have here.

\section{Measles.}

The coefficients are as follows:

$$
\begin{aligned}
& r_{1 e_{2.34}}=+.225 \pm .030 \\
& r_{1 r_{34}}=-.097 \pm .031 \\
& r_{1 c_{4.23}}=-.001 \pm .031
\end{aligned}
$$

Between the death-rate for measles and percentage of illiteracy, there is a moderate positive correlation, which is, however, certainly significant statistically, being more than seven times its probable error. It is, therefore, probable that the extent of illiteracy in a given community plays a significant part in determining the deathrate from this cause.

On the other hand, the death-rate for measles does not appear 
to be significantly correlated with either the percentage of negroes in the population, or the absolute size of the city.

\section{Whooping cough.}

The net coefficients are as follows:

$$
\begin{aligned}
& r_{1 d_{2.34}}=+.070 \pm .031 \\
& r_{1 d_{3.24}}=-.037 \pm .031 \\
& r_{1 d_{4.23}}=+.025 \pm .031
\end{aligned}
$$

None of these coefficients can be regarded as significant in comparison with its probable error. Consequently it may be provisionally concluded that neither the degree of illiteracy in the community, nor the absolute size of its population, nor the percentage of negroes in the population, plays any significant part in determining a community's death-rate from this disease.

\section{Diphiheria.}

The correlation coefficients are :

$$
\begin{aligned}
& r_{1^{2 \cdot 34}}=+.345 \pm .028 \\
& r_{1 e_{3.24}}=+.064 \pm .031 \\
& r_{1 e^{4 \cdot 23}}=-.204 \pm .030
\end{aligned}
$$

The net ccefficient between death-rate from diphtheria and percentage of illiteracy, with absolute size of population and percentage of negroes held eonstant, is the highest net coefficient of illiteracy that we have so far seen. It is more than ten times its probable error and is certainly significant statistically. This result, again, is in accord with what one would expect, since the mortality from this disease depends to such an extent on the manner in which the illness is treated medically.

There is no significant net correlation, when percentages of illiteracy and of negroes are held constant, between the death-rate from diphtheria and the absolute size of the eity.

The apparently significant negative correlation between deathrate from diphtheria and percentage of negroes, when illiteracy and population are held constant, is the first significant negative coefficient that we have encountered. Taken at its face value, it would mean the probably absurd conclusion that the more negroes there were in a community of standard size and average intelligence, the 
smaller would be the death-rate from diphtheria. There is; however, no present justification for accepting this figure at its face value, becanse the magnitude and sign of the coefficient are almost certainly influenced considerably by certain variables, notably geographical distribution of the negro population, which are not taken account of in the present study. Therefore, no weight should be attached to this coefficient pending further detailed analysis.

\section{Pneumonia.}

The net coefficients here are as follows:

$$
\begin{aligned}
& r_{1 / 2.34}=+.463 \pm .025 \\
& r_{1 / 3.24}=-.102 \pm .031 \\
& r_{1 / 4.23}=+.031 \pm .031
\end{aligned}
$$

Here the only significant net correlation is that between the deathrate from pneumonia and the percentage of illiteracy, when both size of population and percentage of negroes are held constant. This is the largest net coeffieient we have yet encountered, and is nearly twenty times its probable error. It indicates that the average ignorance of the population is a distinct and highly significant factor in determining a community's death-rate from this disease. This is precisely what would be expected on the one hand, from the fact that the case fatality of pneumonia is influenced by the intelligence of the medical and nursing care of the case ( $f f$. Pearl, R., 1919), and by the innate constitution of the patient, and, on the other hand, from the fact that any present practice of public health administration has so signally failed in the control of this disease.

The negative correlation between death-rate from pneumonia and absolute size of population, with percentages of illiteracy and of negroes constant, is suggestive, though it cannot be accepted in any way as final until more detailed studies are made. The coeffieient itself cannot be regarded as eertainly significant statistically, though it is probably so. It tends to indicate that the larger the city, other things being equal, the lower the death-rate from pneumonia. This result, however, may be largely due to the existence in the North of a few large cities, notably the boroughs of New York, with a relatively low pneumonia death-rate. This point can be settled when the geographical variables are included in the correlations.

The zero correlation between percentage of increase and the pneu- 
monia death-rate, with other factors constant, appears to indicate that the higher absolute pneumonia death-rate in communities with large numbers of negroes is primarily to be attributed to the ignorance of the negro population rather than to any increased racial susceptibility. But, again, any positive conclusions on this point must await more adequate analysis of the facts.

\section{Diarrhea and enteritis (under 2).}

The coefficients are as follows:

$$
\begin{aligned}
& r_{102.34}=+.715 \pm .015 \\
& r_{193.24}=+.046 \pm .031 \\
& r_{1 g_{4.28}}=-.313 \pm .028
\end{aligned}
$$

Here we have the highest net coefficient between the death-rate and illiteracy, the other factors of size of population and percentage of negroes being held constant. Again, this is precisely what would be expected. The death-rate from this cause depends so largely upon the intelligent home care of infants that one looks for exactly the result which emerges from this statistical study.

There is no correlation between absolute size of city and the death-rate in infants from diarrhea, the other factors being held constant, which is again an entirely reasonable result.

The fairly high and significant negative correlation between this cause of death and percentage of negroes of the population is in all probability a spurious result, which will disappear as other variables, particularly those of geographical distribution, are brought into the correlational nexus.

$$
\text { 8. Puerperal fever. }
$$

The coefficients are as follows:

$$
\begin{aligned}
& r_{1^{h_{34}}}=+.048 \pm .031 \\
& r_{1 r_{3.24}}=+.036 \pm .031 \\
& r_{1 h_{4.23}}=+.029 \pm .031
\end{aligned}
$$

The death-rate from this cause is not sensibly correlated with either illiteracy, absolute size of the city, or proportion of negroes in the population, the other factors being held constant in each case. With the exception of whooping cough this is the only one of the primarily environmental, infectious, communicable diseases which shows no significant correlation between illiteracy and mortality. 
What the explanation is, is not as yet elear, and the whole question of the significance of this finding must be left until our more detailed study is completed.

\section{Tuberculosis of the lungs.}

We come now to the first of a group of diseases in which the constitutional factor unquestionably plays a more important part than in those which have so far been considered. The pertinent correlation coefficients are as follows:

$$
\begin{aligned}
& r_{1 i_{2.34}}=+.010 \pm .031 \\
& r_{1 i_{3.24}}=+.094 \pm .031 \\
& r_{1 i_{4.23}}=+.400 \pm .026
\end{aligned}
$$

There appears to be no significant correlation whatever between percentage of illiteracy and the death-rate from tuberculosis of the lungs, in these cities, when the percentage of negroes and absolute size of population are held constant. This result appears to emphasize the fact, for which there is now so much evidence from so many different sources, that fatal tuberculosis has, as a very large, if not indeed a dominant element in its causation, the inherited constitutional make-up of the individual. We believe that this coefficient will not be sensibly altered by the addition of more variables into the correlational nexus. This result should in no wise be interpreted as indieating that the intelligent cooperation of the patient is not an important factor in the prolongation of life of those stricken with pulmonary tuberculosis. Unquestionably, the intelligence of the patient does play a most significant rôle here, but there is no evidence that this element in the situation would sensibly affect the death rate in a single sample taken at a given time, as is the case here.

There is, further, no evidence that the absolute size of eity, other things being equal, has any sensible influence upon the death-rate from tuberculosis, and the zero coefficient which we find in this case is only what would be expected.

The high positive net coefficient between percentage of negroes in the population and the death-rate from tuberculosis, illiteracy and absolute size of city being constant, is precisely in accord with what is known as the greater susceptibility of the negro to tuberculosis. 


\section{Nephritis.}

The coefficients are as follows:

$$
\begin{aligned}
& r_{1 j_{2.34}}=-.075 \pm .031 \\
& r_{13.24}=+.124 \pm .031 \\
& r_{1 j_{1.23}}=+.410 \pm .026
\end{aligned}
$$

The net correlation between death-rate from nephritis and percentage of illiteracy is sensibly equal to zero, when the other factors are held constant. This is the expected result with a disease in which the constitutional make-up of the individual plays such a preponderant rôle in etiology as is the case with nephritis.

There seems to be a just barely signifieant correlation between the nephritis death-rate and the absolute size of eity, when illiteracy and proportion of negroes in the population are held constant. Whether or not this coefficient can really be regarded as significant, and taken perhaps as an indication of the effect of the strenuous character of life in large cities, must be left for consideration when the results of a more penetrating analysis are in hand. Probably the correlation will disappear when other variables are taken into account.

The high coefficient between the nephritis death-rate and the percentage of negroes in the community probably indicates a really higher racial suseeptibility to this cause of death, but, again, final judgment should be withheld until a more complete analysis has been made.

\section{Cancer.}

The net coefficients are:

$$
\begin{aligned}
& r_{1^{k \cdot 21}}=-.327 \pm .028 \\
& r_{1 k_{3.24}}=+.029 \pm .031 \\
& r_{1^{k \cdot 23}}=+.032 \pm .031
\end{aligned}
$$

The significant negative net correlation between the cancer deathrate and the percentage of illiteracy is difficult to interpret. The $a$ priori expectation would be that this coefficient should be small and positive, but still significant, on the ground that the most effective means of reducing mortality from cancer now known is extremely early operation, which in turn may reasonably be supposed to bespeak a rather high degree of intelligence on the part of the afflicted. It is possible that the negative coefficient arises through faulty diag- 
nosis and registration. May it not be that deaths from cancer among the extremely ignorant elements of the population are usually not diagnosed or registered as such, but as something else? If this were to any considerable extent true, it would result in just such a negative correlation as we find here. It is possible that the addition of other variables, particularly those which involve the correction of age distribution of the population, may shift the result of this coeffcient. Final judgment on the point must, therefore, in this case be reserved until the complete study is finished.

Neither absolute size of eity, nor percentage of negroes in the population are significantly correlated with a death-rate from cancer, when the other two variables are held constant. This result seems entirely reasonable.

\section{Suicide.}

The coefficients are as follows:

$$
\begin{aligned}
& r_{1^{m .34}}=-.179 \pm .030 \\
& r_{1^{n_{3.24}}}=+.100 \pm .031 \\
& r_{1^{m_{423}}}=+.076 \pm .031
\end{aligned}
$$

Here the result, concerning the net correlation of illiteracy with the death-rate, is exactly what would be expected from Miner's (1922) detailed study of the suicide death-rate. The illiterate and the ignorant person generally is not so apt to commit suicide as is his more highly educated and intelligent brother. The net coefficient, while not large, is certainly significant. Neither of the other net coefficients can be considered as statistically significant.

\section{SUMMART.}

This purely preliminary study, by the method of partial correlation, indicates that the percentage of illiteracy in an urban community in this country is a significant factor in influencing unfavorably the death-rate of the community from all causes, and from certain particular causes, notably diarrhea and enteritis (under 2), pneumonia, diphtheria, and measles. The typhoid fever, whooping cough, and puerperal fever death-rates are apparently not significantly correlated with percentage of illiteracy, for probably quite different reasons in the different cases. Furthermore, there is apparently no significant net correlation between the death-rates from either tubereulosis of the lungs, or nephritis with percentage of illiteracy, 
presumably for the reason that in these diseases the innate constitution of the individual is an etiological fact of great importance.

All of the conclusions of this paper are to be regarded as in greater or less degree tentative until a much more intensive study of the problem has been completed, in which corrections will be made for a series of variables not taken into account in this preliminary survey of the field.

Pearl, R.

\section{IITERATURE OITED.}

1921. The vitality of the peoples of America. Amer. Jour. Hygiene, I, 592674.

TALBOT, W.

1916. Adult illiteracy. Ð. \$. Bur. Education Bulletin 35.

YULE, G. U.

1907. On the theory of correlation for any number of variables, treated Pearson, $\mathrm{K}$. by a new system of notation. Proc. Roy. Soe. A., LXXIX, 182-193.

1896. On a form of spurious correlation which may arise when indices are REED, L. J. used in the measurement of organs. Proc. Roy. Soc., LX, 489.

Miner, J. R.

1921. On the correlation between any two functions and its application to the general case of spurious correlation. Jour. Washington Acad. Sci., XI, $449-455$.

1922. Suicide and its relation to climatie and other factors. Amer. Jour. Hyg., Monograph No. 2.

Peari, R.

1919. A statistical discussion of the relative effieacy of different methods of treating pneumonia. Areh. Int. Med., XXIV, 398-403. 